\title{
Controversies Surrounding 0mega-3 Fatty Acids and Prostate Cancer
}

\author{
Xinchun Zhou, MD, PhD, Akram Shalaby, MD, Timothy C. Allen, MD, JD
}

Department of Pathology, University of Mississippi Medical Center, 2500 North State Street, Jackson, MS 39216. xzhou@umc.edu

\begin{abstract}
Context: Omega-3 poly unsaturated fatty acids (omega-3 PUFAs) have been widely studied regarding their associations with pathogenesis, prevention, and treatment of prostate cancer (PCa); however, no agreement has been reached as to whether omega-3 PUFAs are protective by reducing the risk of PCa.

Objective: To provide information to public readers regarding thecontroversies in the effects of individual omega-3 PUFA species, including $\alpha$-Linolenic acid (ALA) eicosapentaenoic acid (EPA), docosapentaenoic acid (DPA), and docosahexaenoic acid (DHA) on PCa, and regarding the causes underlying these controversies.

Data Sources: Research articles archived online related to the effects of omega-3 PUFAs on PCa published in the past four decades. The protective effect of each omega-3 PUFA species on PCa was evaluated in study categories of epidemiological survey/food query, plasma/RBC membrane, prostatic tissue, PCa cell line in vitro, and clinical trial/animal modelin vivo.

Conclusions: Controversies surrounding omega-3 PUFAs and PCa broadly exist in each individual omega-3 PUFAspecies, between omega-3 PUFAs from plant and sea food sources, and among omega-3 PUFAs from sea food sources in every study categories. These controversies are mainly due to: 1) presuming that the levels omega-3 PUFAs in circulation, in RBC membranes and in estimates in diet intake are proportional to those in prostate; 2) using percentage changes to represent alterations in real concentrations of omega-3 PUFAs between two pathological conditions in data analysis, and 3) administrating omega-3 PUFA(s) to PCa cells in vitro with doses far above physiological levels in human prostate in some studies.
\end{abstract}

Prostate cancer (PCa) threatens men's health worldwide ${ }^{1-3}$. In the US, PCa is the most diagnosed non-skin cancer and second leading cause of cancer deaths in men ${ }^{3}$. According to the American Cancer Society's estimates, there will be about 174,650 new cases and 31,620 deaths of prostate cancer in US for 20194. PCa has become a tremendous burden on health care and socioeconomics in our society. In working toward the ultimate goal of eliminating suffering and death from PCa, we need to identify all risk factors, and importantly to know how to modify modifiable risk factors.

Age is the greatest risk factor for PCa. The incidence of PCa strongly increases with age. Based on report on cancer statistics from US Surveillance, Epidemiology and End Results Program from 2000-2008, the incidence rate of prostate cancer was 9.2/100,000 for men aged 40-44 years, but it increased sharply to 984.8/100,000 in men aged 70-74 years ${ }^{5}$. Race is also a well-established risk factor for PCa. There is more than a 60-fold difference in age-adjusted incidence rates between population groups with the highest in African American (AA) men and the lowest in Asian men living in their native countries. In US, PCa is prominently disparate between AAmen and Caucasian Americans (CA) men. As compared to CA men, AA men are younger at onset, have a higher incidence and mortality rate, experience more aggressive clinical courses, and exhibit poor responses to therapies. They also have a higher rate of recurrence and development of advanced PCa, and are 2.4 times more 


\section{Controversies Surrounding Omega-3 Fatty Acids and Prostate Cancer}

likely to die from $\mathrm{PCa}^{6-11}$. A positive family history is highly related to future PCa development, particularly in men who have first-degree relatives affected from $\mathrm{PCa}^{12-14}$. Therefore, family history is considered to be another established risk factor for $\mathrm{PCa}^{15}$.

Age, race, family history and sex are well-established risk factors of $\mathrm{PCa}$, and are not modifiable. Thus, efforts should be made to identify modifiable risk factors in order to prevent occurrence, blocking progression, and improve outcomes of patients with PCa. Modifiable risk factors include life style ${ }^{16}$, obesity ${ }^{17-19}$, sexual activity, smoking ${ }^{20,21}$, and inflammation ${ }^{22,23}$. Among those, dietary intake of fatty acids has been most widely investigated.

Fatty acids are a large group of macromolecules comprised of hydrocarbon chains terminating with carboxylic acid groups. In general, fatty acids play important roles in energy generation, building blocks in cellular membranes, signal-transduction pathways, composition of hormones and complex lipids, and modification of proteins, and energy storage in triglycerides and cholesteryl esters. Importantly, fatty acids are of special significance to PCa. While cancer cells in most malignancies exhibit increased glycolysis and glucose utilization for proliferation ${ }^{24-26}$, PCa cells depend on oxidation of fatty acids as the main energy sourcefor their proliferation. This is accomplished by a dominant uptake of fatty acids over glucose, increased de novo synthesis of fatty acids, accumulation of fatty acids in the form of cholesteryl esters or triglycerides, and up-regulation of enzymes in oxidation of fatty acids ${ }^{27-31}$.

In past decades, numerous research articles and reviews have addressed the influences of fatty acids, especially those with 14-24 carbon chains in individual species, in total and in groups, on PCa. Fatty acids without double bonds in carbon chains are grouped as saturated fatty acids (SFA). Among SFA species, myristic acid has been rarely reported to be associated with risk of PCa. Palmitic acid related to increased PCa risk was reported in few studies ${ }^{32-34}$; and stearic acid inversely related to risk of $\mathrm{PCa}^{34-38}$.

Fatty acids with one double bond in carbon chains are grouped as monounsaturated fatty acids (MUFA). Among those, oleic acid has been the most investigated species, but with a mixed results. Some studies suggest that elevated level of oleic acid, or the ratio oleic to stearic acid in dietary intake, correlates with a high risk of $\mathrm{PCa}^{35,39-41}$ and promotes aggressive behavior of PCacells ${ }^{42,43}$. Others however, suggest that elevated level of oleic acid, or the ratio oleic to stearic acid in dietary intake plays a protective role in the pathogenesis of $\mathrm{PCa}^{37,44-47}$.

Fatty acids with more than one double bond in carbon chains are grouped as polyunsaturated fatty acid (PUFA), including omega-6 (n-6) PUFAs and omega-3 (n-3) PUFAs. It has been reported in several studies that omega-6 PUFAs increase risk and promote progression of $\mathrm{PCa}^{48-55}$. However in a few studies it was shown to reduce the risk of $\mathrm{PCa}^{56,57}$. In one study it was shown not to be related to the risk of $\mathrm{PCa}^{58}$.As compared to omega-6 PUFAs, omega-3 PUFAs are more involved in pathogenesis, progression, prevention, and treatment of PCa.

Omega-3 PUFAs are a group of polyunsaturated fatty acids with the first double bond in the third carbon position from the methyl terminal. Main omega-3 PUFA species and their metabolic pathwaysare shown in Figure 1. Human beings can only form carbon-carbon double bonds after the 9th carbon from the methyl end of a fatty acid. Therefore, $\alpha$-Linolenic acid (ALA) must be obtained from the diet and is the only essential fatty acid among omega-3 PUFAs. ALA is widely present in plant oils, such as flaxseed, soybean, and canola oils ${ }^{59}$. Other important omega-3 PUFAs are eicosapentaenoic acid (EPA), docosapentaenoic acid (DPA) and docosahexaenoic acid (DHA). Although these omega-3 PUFAs can be converted from ALA, conversion rates from ALA to other omega-3 PUFAs, especially to DHA are low ${ }^{60}$. Thus dietary intake is the main source for these omega-3 PUFAs. Unlike ALA, these omega-3 PUFAs are present in sea foods such as fish, fish oils, and krill oils, because sea fishes accumulate omega-3 PUFAs in their tissues through consumption of phytoplankton that themselves consumed microalgae, which originally synthesize omega-3 PUFAs ${ }^{59}$. 


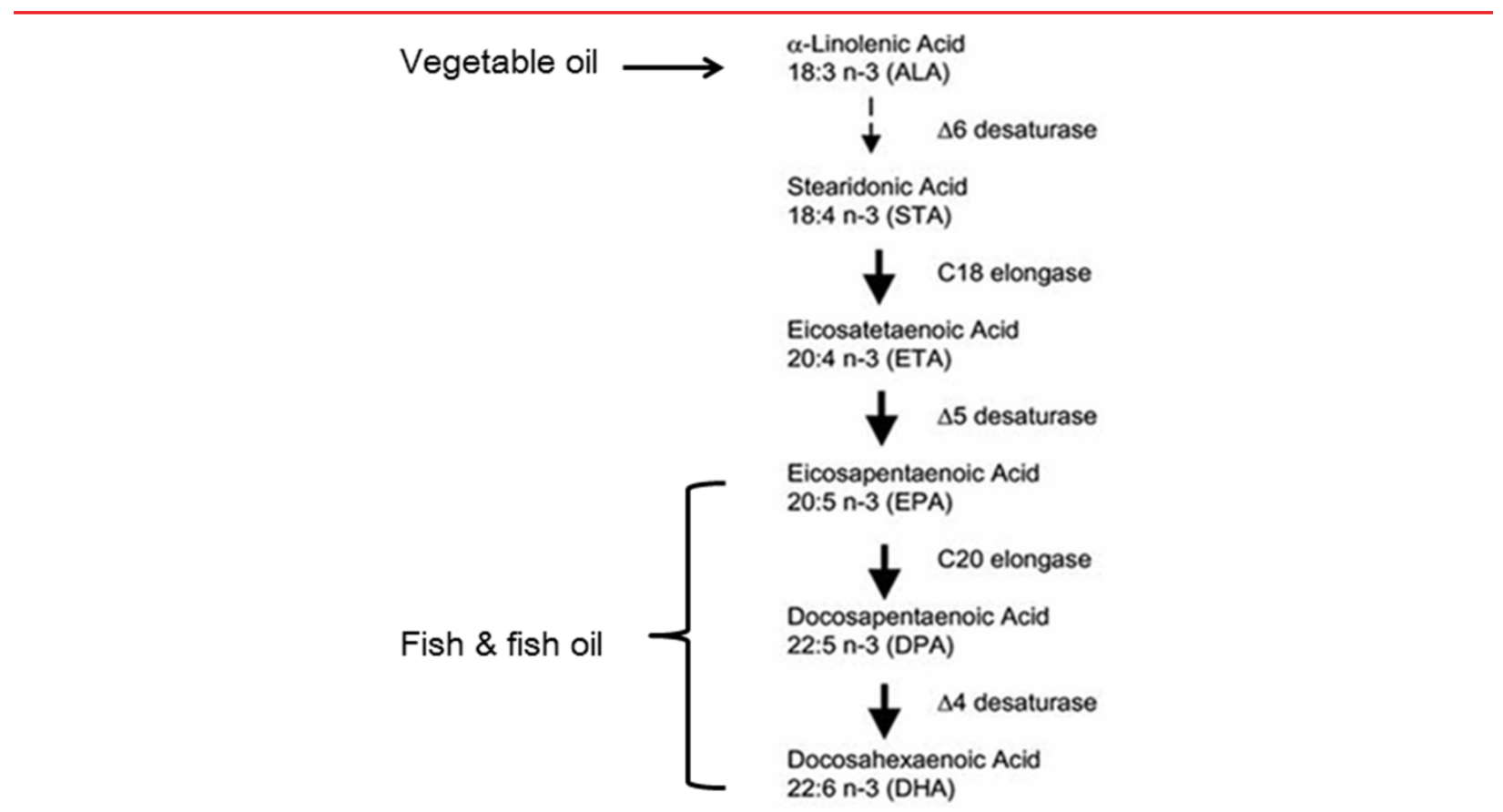

Figure1. Main omega-3 poly unsaturated fatty acid species (PUFAs) and their metabolic pathways.

This review evaluates the effects of each of main omega-3 PUFA species, namely, ALA, EPA, DPA and DHA separately on PCa.

\section{Effects of $\alpha$-linolenic Acid (ALA) on PCa}

Chua et al. found that high intake of ALA may reduce risk of prostate cancer, while intake of other long-chain omega-3 fatty acids did not have a significant effect ${ }^{61}$. Fu et al also found that dietary ALA was inversely associated with PCa risk ${ }^{62}$. However, Brouwer et al. indicated in two reviews that the risk of prostate cancer increased in men with a high intake of ALA, although high ALA intake was associated with reduced risk of fatal heart disease in prospective cohort studies ${ }^{63,64}$. The influences of ALA on PCa from individual studies were also inconsistent in different study categories as shown in Table 1. In study category of Epidemiological Survey/ Food Query, seven studies revealed that higher intake of ALA was associated with an increased risk of PCa ${ }^{32,46}$, 58,65-68. Only one study suggested that ALA in dietary intake was inversely associated with PCa risk ${ }^{62}$. In study category of Plasm/RBC Membrane, the association of ALA in plasma or in phospholipids ofRBC membranes with risk of PCa was very controversial: ALA related to decreased risk of PCa in seven studies ${ }^{61,62,69-73}$, increased risk of PCa in five studies $32,46,63,74,75$, and no correlation to PCa in four studies $67,74,76,77$. In study category of Prostatic Tissue, only two studies were conducted regarding thecorrelation of prostatic level of ALA with the risk of PCa: Christensen et al. found that increased prostatic level of ALA correlated with the presence of $\mathrm{PCa}$, and to higher level of PSA in men with PCa ${ }^{74}$;Azrad et al. alsofound that 1) the level of prostatic ALA was independent of the amount of ALA consumed, and 2) the level of prostatic ALA was significantly associated with patient's PSA value $(P=0.028)$ and expression level of Ki67 $(P=0.037){ }^{85}$. No study showed an association of prostatic ALA level with decreased PCa risk. Two in vitrostudies found that ALA was able to inhibit PC-3 and LNCaP cell proliferation through regulating genes involved in fatty acid synthesis, inflammation, cell cycle, and apoptosis ${ }^{80}$; and inhibit PC-3 and RWPE-1 cells proliferation through changing production of interleukin-6 (IL-6), tumor necrosis factor- $\alpha$ (TNF- $\alpha$ ), lipoxin A4, and free radical generation ${ }^{71}$. However one in vitrostudy indicated that ALA, as well as other PUFAs at low concentrations $(1 \mathrm{ng} / \mathrm{ml})$ was able to promote proliferation 


\section{Controversies Surrounding Omega-3 Fatty Acids and Prostate Cancer}

of many human and animal cell lines ${ }^{81}$. In study category of Clinical Trial/Animal Model in vivo, several studies on human clinical trials and on animal models suggest that increase in dietary intake of ALA show decreased growth potential in $\mathrm{PCa}^{85,86,93,94}$. In a multisite, randomized controlled trial the Demark-Wahnefried research team tested the effects of low-fat vs. flaxseed-supplemented (rich in ALA) diets on the biology of the prostate and other biomarkers. They found that proliferation rates were significantly lower $(P=0.002)$ among men who took flaxseed-supplemented diet ${ }^{84}$. Another clinical trial (The Alpha Omega Trial) involved1,622 patients aged 60-80 years with a history of myocardial infarction and an initial PSA concentration $<4 \mathrm{ng} / \mathrm{ml}$. In this study, patients received additional amount of $2 \mathrm{~g}$ of ALA per day slightly increased PSA by $0.10 \mathrm{ng} / \mathrm{ml}$, but no evidence showed a clinically significant effect of ALA intake on PCa risk ${ }^{76}$. Therefore, the effects of ALA on PCa are controversial. ALA may reduce risk and inhibit progression of PCa in some studies; but it increase risk and promote progression of PCa in other studies.

Table1. Influence of $\alpha$-linolenic acid (ALA) on PCa

\begin{tabular}{|c|c|c|c|}
\hline Study Category & Effects on PCa & \# of Studies & References \\
\hline \multicolumn{4}{|c|}{ Epidemiological Survey/Food Query } \\
\hline & Decreased risk & 2 & 39,62 \\
\hline & Increased risk & 8 & $32,46,58,65-68,78$ \\
\hline & No association & 2 & 47,79 \\
\hline \multicolumn{4}{|c|}{ Plasma/RBC Membrane } \\
\hline & Decreased risk & 7 & $61,62,69-73$ \\
\hline & Increased risk & 5 & $32,46,63,74,75$ \\
\hline & No association & 4 & $67,74,76,77$ \\
\hline \multicolumn{4}{|l|}{\begin{tabular}{|l|} 
Prostatic Tissue \\
\end{tabular}} \\
\hline & Increased risk & 2 & 74,76 \\
\hline \multicolumn{4}{|c|}{ In vitro in PCa Cell Line } \\
\hline & Decreased risk & 2 & 71,80 \\
\hline & Increased risk & 1 & 81 \\
\hline \multicolumn{4}{|c|}{ Clinical Trial/Animal Model in vivo } \\
\hline & Decreased risk & 5 & $72,73,82-84$ \\
\hline & No association & 1 & 76 \\
\hline
\end{tabular}

\section{Effects of Eicosapentaenoic Acid (EPA) on PCa}

It was suggested 50 years ago that high fish consumption among the Eskimos of Greenland contributed to their low death rate from coronary heart disease ${ }^{86}$. In 1980's, Karmali et al. suggested that fish oil can inhibit growth of mammary and prostatic tumor cells ${ }^{87,88}$. This could be because fish and fish oil contain large amount of omega-3 PUFAs, including eicosapentaenoic acid (EPA). EPA has a 20-carbon chain and five cis double bonds. EPA has been extensively investigated as to its relationship to human diseases, including PCa. As shown in Table 2, in study category of Epidemiological Survey/Food Query, four studies conducted in human PCa patients were in agreement with Karmali et al. that more dietary fish intakeis associated with a lower risk of $\mathrm{PCa}^{58,89-91}$. But three studies conclude contrarily that more fish intake in diet was associated with a high risk of $\mathrm{PCa}^{(78,104,105)}$. Four studies claimed that fish intake or circulatory level of EPA is not associated with risk of PCa ${ }^{32,79,92,93}$.

In study category of Plasma/RBC Membrane, the level of EPA in plasma or in phospholipids in RBC membranes has been related to decreased risk of PCa. One study suggests that the circulatory level of EPA is higher in men without prostatic diseases than patients with benign prostatic hyperplasia (BPH), and lowest in patients with 


\section{Controversies Surrounding Omega-3 Fatty Acids and Prostate Cancer}

$\mathrm{PCa}^{48}$. Two other studies found circulatory EPA inversely correlated to PCa risk as well ${ }^{90,94}$. Surprisingly, no correlation was found between EPA level and PCa risk in seven studies 32, 55, 74, 77, 93, 95, 96.

Table2. Influence of eicosapentaenoic acid (EPA) on PCa

\begin{tabular}{|c|c|c|c|}
\hline Study Type & Effect on PCa & \# of Studies & References \\
\hline \multicolumn{4}{|c|}{ Epidemiological Survey/Food Query } \\
\hline & Decreased & 4 & $58,89-91$ \\
\hline & Increased risk & 3 & $67,100,102$ \\
\hline & No association & 4 & $32,79,92,93$ \\
\hline \multicolumn{4}{|c|}{ Plasma/RBCMembrane } \\
\hline & Decreased risk & 3 & $48,90,94$ \\
\hline & Increased risk & 3 & $67,100,102$ \\
\hline & No association & 7 & $32,55,74,77,93,95,96$ \\
\hline \multicolumn{4}{|c|}{ Prostatic Tissue } \\
\hline & Decreased risk & 4 & $72,97-99$ \\
\hline & Increased risk & 1 & 100 \\
\hline & No association & 2 & 74,95 \\
\hline \multicolumn{4}{|c|}{ In vitro in PCa Cell line } \\
\hline & Improve outcomes & 2 & 103,104 \\
\hline & Inhibit proliferation & 11 & $53,71,80,97,101,105-110$ \\
\hline & Stimulate proliferation & 1 & 81 \\
\hline \multicolumn{4}{|c|}{ Clinical Trial/ Animal Modelin vivo } \\
\hline & Decreased risk & 2 & 100,111 \\
\hline & No association & 2 & 95,112 \\
\hline
\end{tabular}

In prostatic tissues, higher EPA levels correlate with a decreased risk of PCa, and improved patient's clinical outcomes ${ }^{72,97-99}$. But in one study, higher EPA levels correlate with increased risk of $\mathrm{PCa}^{100}$. No correlation was found between prostatic EPA level and risk of PCa in two studies ${ }^{(86,107)}$. In 1985, Begin et al. found that when human cancer cells and normal human fibroblasts were co-cultured in the absence of PUFAs, the malignant cells overgrew the normal ones; when eicosapentaenoic acid (EPA, 20:5n-3) and other PUFAs were added to the co-cultures, the normal cells outgrew the malignant cells ${ }^{101}$. Since then EPA has been found to be able to enhance therapeutic effects ${ }^{(112,113)}$ and inhibit proliferation of many PCa cell lines ${ }^{(53,83,90,109,114-120)}$. Only one study indicated that EPA actually promoted prostatic cell lines growth at low concentrations $(1 \mathrm{ng} / \mathrm{ml})$. But at higher concentrations, EPA did inhibit prostate cell growth ${ }^{(91)}$.

EPA was found to be able to reduce PCa risk in two clinical trials ${ }^{(105,121)}$, and did not correlate PCa risk in other two studies ${ }^{(107,122)}$. Recently, the Guertin research team ${ }^{113}$ attempted to evaluate the effects of long-chain omega-3 polyunsaturated fatty acids, more precisely eicosapentaenoic acid monoacylglyceride (MAG-EPA) supplementation, on prostate cancer proliferation, inflammatory mediators, and quality of life among men who will undergo radical prostatectomy. They proposed a phase IIb, randomized, double-blind placebo-controlled trial, in which MAG-EPA supplementation was administered to 130 men who will undergo radical prostatectomy as treatment for a prostate cancer of Gleason score $\geq 7$. Participants will be randomized to 6 capsules of $625 \mathrm{mg}$ of fish oil (MAG-EPA, per capsule containing $500 \mathrm{mg}$ of EPA) daily or to identically looking capsules of high oleic acid sunflower oil (HOSO) as placebo. This study is ongoing. Thus, conclusions on risk or protective effect of EPA 


\section{Controversies Surrounding Omega-3 Fatty Acids and Prostate Cancer}

to PCa were highly inconsistent. Taking together, EPA has been widely investigated as to its relationship with risk and progression of PCa. Although EPA shows effects in decreasing risk and improving outcomes of PCa in many studies, it also shows effects in increasing risk and stimulating proliferation of PCa in some studies.

\section{Effects of Docosapentaenoic Acid (DPA) on PCa}

Docosapentaenoic acid (DPA, specifically refer to omega-3 DPA isomer) is a member of omega-3 PUFAs intermediary between EPA and DHA. As compared to its substrate EPA and its product DHA, DPA has been less studied regardingits association with risk of PCa.As shown in Table 3, in study category of Epidemiological Survey/Food Query, three studies concluded that higher DPA play a role in reducing risk of $\mathrm{PCa}^{62,100,102}$. For example, in a dose-response meta-analysis of prospective observational studies, Fu et al. found that a $0.2 \%$ increase in blood DPAconcentration was associated with a 3\% reduced risk of PCa $\left(P=0.05\right.$ for linear trend) ${ }^{62}$. No relationship between DPA and PCa was reported in two studies ${ }^{32,47}$.

In study category of Plasma/RBC Membrane, higher concentration of DPA in plasma or in phospholipids in RBC membranes related to decreased risk of PCa were reported six studies ${ }^{62,67,72,73,100,102}$. One study indicated that no association between circulatory level of DPA and the risk of $\mathrm{PCa}^{32}$. In prostatic tissues, the concentration of prostatic DPA was reported to correlate to decreased risk of PCa in one study ${ }^{114}$, increased risk of PCa in one study ${ }^{56}$, and no association with risk of PCa in one study ${ }^{100}$. No study has been specifically conducted to investigate effects of DPA on proliferations in vitro in PCa cell lines. In vivo study, DPA togetherwith other omega-3 PUFAs demonstrated to be able to decrease risk of PCa in two phase II clinical trials ${ }^{83,100}$ and in two animal models ${ }^{72,114}$. One in vivo in animal model study failed to demonstrate an association between DPA and risk of PCa ${ }^{115}$.In summary, it is still controversial in the effect of DPA on risk of PCa, although most studies favored that DPA correlated to decreased risk of PCa.

Table3. Influence of docosapentaenoic acid (DPA) on PCa

\begin{tabular}{|c|c|c|c|}
\hline Study Types & Effect on PCa & \# of Studies & References \\
\hline \multicolumn{4}{|c|}{ Epidemiological Survey/Food Query } \\
\hline & Decreased risk & 3 & $62,100,102$ \\
\hline & No association & 2 & 32,47 \\
\hline \multicolumn{4}{|c|}{ Plasma/RBC Membrane } \\
\hline & Decreased risk & 6 & $62,67,72,73,100,102$ \\
\hline & Increased risk & 3 & $38,57,70$ \\
\hline & No association & 1 & 32 \\
\hline \multicolumn{4}{|c|}{ Prostatic Tissue } \\
\hline & Decreased risk & 1 & 114 \\
\hline & Increased risk & 1 & 56 \\
\hline & No association & 1 & 100 \\
\hline \multicolumn{4}{|c|}{ Clinical Trial/Animal Model in vivo } \\
\hline & Decreased risk & 4 & $72,83,100,114$ \\
\hline & No association & 1 & 115 \\
\hline
\end{tabular}

\section{Effects of Docosahexaenoic Acid (DHA) on PCa}

Docosahexaenoic acid (DHA) is a carboxylic acid with a 22-carbon chain and six cis double bonds. DHA cannot be synthesized de novo in human, and therefore must be obtained in the diet primarily through fish, nutraceuticals, and functional foods (foodshave a potentially positive effect on health beyond basic nutrition) ${ }^{116}$ 


\section{Controversies Surrounding Omega-3 Fatty Acids and Prostate Cancer}

or converted within the body from $\alpha$-linolenic acid (ALA). In addition to playing a very important role in human pathophysiology, such as in brain ${ }^{(129)}$ and cardiovascular system ${ }^{(130)}$, DHA also has an impact on occurrence and progression of many cancers by inducing cancer cell apoptosis, reducing cancer cells proliferation in vitro and in vivo through potential mechanisms including membrane incorporation, lipid peroxidation, and stalling progress of cell cycles ${ }^{(131-133)}$. The relationship between DHA and PCa has been widely investigated as listed in Table 4.

Table4. Influence of docosahexaenoic acid (DHA) on PCa

\begin{tabular}{|c|c|c|c|}
\hline Study Type & Effect on PCa & \# of Studies & References \\
\hline \multicolumn{4}{|c|}{ Epidemiological Survey/ Food Query } \\
\hline & Decreased risk & 2 & 58,118 \\
\hline & Improve outcomes & 1 & 89 \\
\hline & Increased risk & 4 & $67,93,100,102$ \\
\hline & No association & 2 & 32,92 \\
\hline \multicolumn{4}{|c|}{ Plasma/RBC Membrane } \\
\hline & Decreased risk & 5 & $48,55,71,90,117$ \\
\hline & Increased risk & 3 & $67,93,100$ \\
\hline & No association & 4 & $32,74,77,95$ \\
\hline \multicolumn{4}{|c|}{ Prostatic Tissue } \\
\hline & No association & 4 & $56,74,100,119$ \\
\hline \multicolumn{4}{|c|}{ In vitro in PCa Cell Line } \\
\hline & improved outcomes & 2 & $120-122$ \\
\hline & Inhibit proliferation & 10 & $53,80,104,105,109,110,122-125$ \\
\hline & No association & 2 & 71,74 \\
\hline \multicolumn{4}{|c|}{ Clinical trial/Animal Model in vivo } \\
\hline & Decreased risk & 4 & $83,88,99,114,115$ \\
\hline & No association & 1 & 100 \\
\hline
\end{tabular}

In study category of Epidemiological Survey/Food Query, the association between PCa risk and DHA level in dietary intake or in phospholipids in RBC membranes was evaluated in two studies. One study followed 47,866 US men aged 40-75 year-old with no cancer history for 14 years, to prospectively evaluate the association of DHA in diet intake and risk of PCa. Another study examined the relationship between PCa risk and DHA (and EPA) level in phospholipids in RBC membranes in a population-based case-control studyinvolving 317 PCa cases and 480 age-matched community controls. Both studies concluded that high level of DHA in dietary intake or in phospholipids in RBC membranes relatedto decreased risk of PCa ${ }^{58,90}$. One study prospectively evaluated the association between diet intakes of PUFAs including DHA and risk of PCa in patients diagnosed with PCa: men consuming fish 5 times/wk. or more had a 48\% lower risk of PCa death than did men consuming fish less than once weekly ${ }^{89}$. These three studies hinted that DHA played a protective role either in preventing prostatic oncogenesis, or on PCa progression. However conclusions from other four studies were contrary: higher DHA levels in dietary intakecorrelated with higher grade of $\mathrm{PCa}{ }^{(76,103-105)}$. Two studies reported that there was no correlation between level of DHA in dietary intake and PCa risk ${ }^{(32,102)}$. Similar controversies were found in study category of Plasma/RBC Membrane, in which the concentration of DHA in plasma or in phospholipids in RBC membranes related to decreased risk of PCa in five studies $48,55,71,90,117$, increased risk of PCa in three studies ${ }^{67,93,100}$, and did not relate to risk of PCa in four studies ${ }^{32,74,77,95}$. 


\section{Controversies Surrounding Omega-3 Fatty Acids and Prostate Cancer}

In study category of Prostatic Tissue, there was no significant difference in DHA level between PCa and adjacent benign prostatic tissues, between PCa and benign prostatic hyperplasia (BPH),or between PCa with and without progressionin four studies $56,74,100,119$.

A total of fifteen studies regarding the correlation of DHA with PCarisk were included in study category of In vitro in PCa Cell Line. Surprisingly, no study showed that DHA correlated with increased risk of PCa. Except for two studies that showed no relationship between DHA and risk of $\mathrm{PCa}{ }^{71,74}$, the remaining thirteen studies concluded that DHA either improves therapeutic effects of androgen depletion therapy (ADT) and other antitumor therapeutic agents ${ }^{120,126}$, or inhibits proliferation of many prostatic cells,such as PC-3, LNCaP, RWPE-1 and DU-145 by DHA at doses ranged from $10 \mu \mathrm{M}$ to $200 \mu \mathrm{M}^{53,80,104,105,109,110,122-125}$. Mechanisms underlying inhibitory effects cancer cells proliferation by DHAinvolved numerous pathways such as inhibiting fatty acid synthase, accelerating androgen receptor degradation, and altering signal transduction in AKT,JAK1, STAT1, ERK1/2, JNK and IFN- $\gamma$ etc.

In study category of Clinical Trials/Animal Model in vivo, there were six studies including two clinical trials and four animal models. Three studies used xenograft animal model, in which animal fed with diet containing omega-3 PUFAs including high proportion DHA. The results showed that animals fed with a diet rich inomega-3 PUFAs had significantly smaller tumor volume, significantly inhibited growth, slowed down the growth of castration-resistant tumors, smaller tumor cells with more connective tissue in histological sections, and less intense immunochemical staining for human prostatic acid phosphatase ${ }^{88,99,114}$, as compared to animals fed with a diet rich in omega- 6 PUFAs. Another study report that $100 \%$ of animals fed with refined, westernized AIN-93-based diets containing corn oil developed PCa by 12 months of age spontaneously; while animals fed with a diet replaced by 50\% menhaden oil, contain omega-3 PUFAs, such as DHA escaped from development of spontaneous $\mathrm{PCa}^{115}$. One clinical trial also reported that DHA can decrease risk of $\mathrm{PCa}^{83}$; and another clinical trial suggested no association between DHA and risk of $\mathrm{PCa}^{100}$.Similar to other omega-3 PUFAs discussed above, DHA shows controversial effects on PCa. Some studies suggest that DPA decreases risk and improves outcome of PCa; others indicate it increases risk of PCa; and several studies show no relationship between DPA and risk of PCa.

\section{Possibilities Underlying the Controversies}

Seemingly a panacea, omega-3 PUFAs have been tried for prevention and treatment of a wide spectrum of diseases. For cardiovascular diseases, omega-3 PUFAs could benefit to cardiovascular functions through counteracting the atherosclerotic process ${ }^{127-129}$, preventing hypertension ${ }^{130}$, lowering cardiovascular mortality 131, and reduce sudden death caused by cardiac arrhythmias and all-cause mortality in patients with known coronary heart disease ${ }^{132}$. Epidemiological studies have revealed that omega-3 PUFAs are associated with incidence and progression of many cancers, such as breast ${ }^{133}$, colon cancer ${ }^{134}$, liver cancer ${ }^{135}$, and pancreatic cancer ${ }^{136}$. But omega-3 PUFAs were most extensively studied on their associations with incidence and mortality rate, progression, prevention, and treatment of PCa. This could be because PCa is unique in dominantly using fatty acids as fuels in energy production. Importantly, PCa has a mostly indolent natural history and long overall survival after diagnosis, providing an opportunity for exploration of non aggressive interventions such as diet and lifestyle to modifythe natural clinical course and outcome of PCa.

Previously studies on the associations of omega-3 PUFAs with PCa have greatly helped in seeking modifiable factors to influence pathogenesis, progression, prevention, and treatment of PCa. However, these studies have not reached an agreement on the pros and cons of each omega-3 PUFA species to PCa. Instead, conclusions are highly controversial, inconsistent and even contrary within each individual omega-3 PUFA species, between PUFAs derived from plants and sea foods, and among omega-3 PUFA species derived from sea foods in every study category. The following possibly contribute to the controversies. 
Anderson et al. ${ }^{137}$ summarized several factors related to the inconsistency. For example, using food frequency questionnaires in nutritional epidemiology as a method of assessing dietary intake may produce inaccurate results, because questionnaires are subject to recall bias and the food composition databases they are based upon may lack precision in quantifying actual nutrient intake. Alternatively, erythrocytes have been used as biomarkers for dietary intake of fatty acids; however, they lack complete accuracy too. Some sources indicate erythrocyte membrane fatty acid composition is reflective of a typical diet at approximately 4 months ${ }^{138}$, whereas other research suggests levels of fatty acids in RBC membrane reflect dietary intake after 3 weeks ${ }^{139}$,

${ }^{140}$. The levels of fatty acids are not necessarily and accurately proportioned to that estimated in dietary intake and measured in circulation or in phospholipids in RBC membranes,as assumed previously ${ }^{141,142}$. In addition, prostate cancer exhibits enhanced rates of de novo fatty acids synthesis, which makesthe fatty acid profile in PCa cells differ from that in circulation ${ }^{143-145}$. Neither are prostatic concentrations of majority of fatty acids proportional to the amount estimated from dietary intake, nor does the presence of prostate cancer affect fatty acid consumption in other tissues such as adipose tissue or erythrocyte membranes ${ }^{77}$. Therefore only prostatic fatty acid profiles are most closely correlated with pathological changes in prostate as suggested by Moreel et al. ${ }^{100}$. However, studies on lipid profiling including omega-3 PUFAs performed on prostatic tissues were limited. Especially, lipid profiling on prostatic tissues from African American men wasrare: in this study, there were only four research articles performed lipid profiling on prostatic tissues in AA men ${ }^{54,95,97,146}$. Recently, Figiel S et al ${ }^{97}$ found that DPA in peri-prostatic adipose tissues from both indolent and aggressive PCa was significantly lower in African-Caribbean men than in CA men. More data from lipid profiling on prostatic tissues from AAand CA men in the US are needed in helping to explain why incidence and mortality rate of PCa are prominently disparate between these two races.

Another important issue possibly responsible for the inconsistencies among studies could be neglected: the percentage of certain targeting fatty acids out of total fatty acids (sum of total detected fatty acid species) was used in data analysis in most previous studies. First, percentage changes were not equal, proportion or even contrary to actually changes in absolute concentrations between PCa and benign prostatic tissues. Second, total fatty acids were determined by varied numbers and species of fatty acids among studies, making results not being comparable. It is better to use absolute concentration (such as micromole, or nanomole per gram prostatic tissues, or per gram protein) to compare difference between PCa and BPT in data analysis.

All four omega-3 PUFA species, especially EPA and DHA were investigated on their effects on PCa using PCa cell line in vitro. Interestingly, Both EPA and DHA showed the ability to inhibit PCa cell proliferation in vitro in most majority studies. These inhibiting effects were dose-dependent (concentrations ranged 10-200 $\mu \mathrm{M}$ ). It cannot be excluded that these inhibiting effects may have been caused bytoxic effects from free fatty acids (EPA and DHA) in doses far above tolerance of prostatic cells in physiologic conditions, because when free fatty acid levelsare too high they may giverise to a large number of toxic compounds (isoprostanes and other nonenzymatic products) ${ }^{147}$. Our recent study showed that the concentration of free form DHA in PCa was less than $0.007 \mathrm{nmol} / \mathrm{mg}$ in PCa tissues, which was $1.9 \times 10^{-5}$ less than total DHA (134 nmol/mg) in PCa tissues. Whether proliferations of PCa cells are inhibited by biological effects of EPA and DHA, or by their toxic effects require further investigation.

In addition, differences in study methods, size of samples, geographic locations, and studied populations might also contribute to the controversies among studies.

\section{CONCLUSIONS}

Whether omega-3 PUFAs have risk, protective, or no effect on PCa remains highly controversial. Such controversies are broadly exist in each individual omega-3 PUFAspecies, between omega-3 PUFAs originated from plants and 
sea foods, and among omega-3 PUFAs originated from sea foods in every study categories. These controversies are mainly owe to: 1) presuming that prostatic levels of omega-3 PUFAs proportion to that in circulation, in phospholipids in RBC membranes, and in estimates from diet intake; 2) using percentagesof omega-3 PUFAsto represent changes in absolute concentrations between two pathological conditions in data analysis, and 3) treating PCa cells in vitroby omega-3 PUFA(s) with dosesfar abovephysiological level in prostatic cells.

\section{REFERENCES}

1. Torre LA, Bray F, Siegel RL, Ferlay J, Lortet-Tieulent J, Jemal A. Global cancer statistics, 2012. CA: a cancer journal for clinicians. 2015;65(2):87-108.

2. Crawford ED. Understanding the epidemiology, natural history, and key pathways involved in prostate cancer. Urology. 2009;73(5 Suppl):S4-10.

3. Parkin DM, Pisani P, Ferlay J. Global cancer statistics. CA: a cancer journal for clinicians. 1999;49(1):33-64, 31.

4. Jemal A, Center MM, DeSantis C, Ward EM. Global patterns of cancer incidence and mortality rates and trends. Cancer epidemiology, biomarkers \& prevention : a publication of the American Association for Cancer Research, cosponsored by the American Society of Preventive Oncology. 2010;19(8):1893-1907.

5. Surveillance E, and End Results Program (SEER) of the National Cancer Institute. Fast Stats: An interactive tool for access to SEER cancer statistics. Bethesda, MD: SEER, National Cancer Institute. 2011.

6. Edwards BK, Noone AM, Mariotto AB et al. Annual Report to the Nation on the status of cancer, 1975-2010, featuring prevalence of comorbidity and impact on survival among persons with lung, colorectal, breast, or prostate cancer. Cancer. 2014;120(9):1290-1314.

7. Parker PM, Rice KR, Sterbis JR et al. Prostate cancer in men less than the age of 50: a comparison of race and outcomes. Urology. 2011;78(1):110-115.

8. Moses KA, Chen LY, Sjoberg DD, Bernstein M, Touijer KA. Black and White men younger than 50 years of age demonstrate similar outcomes after radical prostatectomy. BMC urology. 2014;14:98.

9. Powell IJ, Banerjee M, Novallo M et al. Prostate cancer biochemical recurrence stage for stageimore frequent among African-American than white men with locally advanced but not organ-confined disease. Urology. 2000;55(2):246-251.

10. Chornokur G, Dalton K, Borysova ME, Kumar NB. Disparities at presentation, diagnosis, treatment, and survival in African American men, affected by prostate cancer. The Prostate. 2011;71(9):985-997.

11. Latini DM, Elkin EP, Cooperberg MR, Sadetsky N, Duchane J, Carroll PR. Differences in clinical characteristics and disease-free survival for Latino, African American, and non-Latino white men with localized prostate cancer: data from CaPSURE. Cancer. 2006;106(4):789-795.

12. Lichtenstein P, Holm NV, Verkasalo PK et al. Environmental and heritable factors in the causation of cancer-analyses of cohorts of twins from Sweden, Denmark, and Finland. The New England journal of medicine. 2000;343(2):78-85.

13. Brandt A, Bermejo JL, Sundquist J, Hemminki K. Age-specific risk of incident prostate cancer and risk of death from prostate cancer defined by the number of affected family members. European urology. 2010;58(2):275-280.

14. Frank C, Fallah M, Ji J, Sundquist J, Hemminki K. The population impact of familial cancer, a major cause of cancer. International journal of cancer. 2014;134(8):1899-1906. 
15. Carter HB, Albertsen PC, Barry MJ et al. Early detection of prostate cancer: AUA Guideline. The Journal of urology. 2013;190(2):419-426.

16. Putnam SD, Cerhan JR, Parker AS et al. Lifestyle and anthropometric risk factors for prostate cancer in a cohort of Iowa men. Annals of epidemiology. 2000;10(6):361-369.

17. Thomas JA, 2nd, Freedland SJ. Obesity and prostate cancer: collateral damage in the battle of the bulge. Frontiers in bioscience (Scholar edition). 2011;3:594-605.

18. Andersson SO, Wolk A, Bergstrom R et al. Body size and prostate cancer: a 20-year follow-up study among 135006 Swedish construction workers. Journal of the National Cancer Institute. 1997;89(5):385-389.

19. Giovannucci E, Rimm EB, Liu Y et al. Body mass index and risk of prostate cancer in U.S. health professionals. Journal of the National Cancer Institute. 2003;95(16):1240-1244.

20. Plaskon LA, Penson DF, Vaughan TL, Stanford JL. Cigarette smoking and risk of prostate cancer in middleaged men. Cancer epidemiology, biomarkers \& prevention : a publication of the American Association for Cancer Research, cosponsored by the American Society of Preventive Oncology. 2003;12(7):604-609.

21. De Nunzio C, Andriole GL, Thompson IM, Jr., Freedland SJ. Smoking and Prostate Cancer: A Systematic Review. European urology focus. 2015;1(1):28-38.

22. Kuang AG, Nickel JC, Andriole GL, Castro-Santamaria R, Freedland SJ, Moreira DM. Both acute and chronic inflammation are associated with less perineural invasion in men with prostate cancer on repeat biopsy. BJU international. 2019;123(1):91-97.

23. Sfanos KS, Yegnasubramanian S, Nelson WG, De Marzo AM. The inflammatory microenvironment and microbiome in prostate cancer development. Nature reviews Urology. 2018;15(1):11-24.

24. Warburg 0. On respiratory impairment in cancer cells. Science. 1956;124(3215):269-270.

25. Gatenby RA, Gillies RJ. Why do cancers have high aerobic glycolysis? Nature reviews Cancer. 2004;4(11):891899.

26. Hsu PP, Sabatini DM. Cancer cell metabolism: Warburg and beyond. Cell. 2008;134(5):703-707.

27. Liu Y. Fatty acid oxidation is a dominant bioenergetic pathway in prostate cancer. Prostate cancer and prostatic diseases. 2006;9(3):230-234.

28. Rhodes DR, Yu J, Shanker $\mathrm{K}$ et al. Large-scale meta-analysis of cancer microarray data identifies common transcriptional profiles of neoplastic transformation and progression. Proc Natl Acad Sci U S A. 2004;101(25):9309-9314.

29. Yue S, Li J, Lee SY et al. Cholesteryl ester accumulation induced by PTEN loss and PI3K/AKT activation underlies human prostate cancer aggressiveness. Cell metabolism. 2014;19(3):393-406.

30. Lloyd MD, Yevglevskis M, Lee GL, Wood PJ, Threadgill MD, Woodman TJ. alpha- Methylacyl-CoA racemase (AMACR): metabolic enzyme, drug metabolizer and cancer marker P504S. Progress in lipid research. 2013;52(2):220-230.

31. Welsh JB, Sapinoso LM, Su AI et al. Analysis of gene expression identifies candidate markers and pharmacological targets in prostate cancer. Cancer research. 2001;61(16):5974-5978.

32. Harvei S, Bjerve KS, Tretli S, Jellum E, Robsahm TE, Vatten L. Prediagnostic level of fatty acids in serum phospholipids: omega-3 and omega- 6 fatty acids and the risk of prostate cancer. International journal of cancer. 1997;71(4):545-551. 
33. Park SY, Wilkens LR, Henning SM et al. Circulating fatty acids and prostate cancer risk in a nested casecontrol study: the Multiethnic Cohort. Cancer causes \& control : CCC. 2009;20(2):211-223.

34. Crowe FL, Allen NE, Appleby PN et al. Fatty acid composition of plasma phospholipids and risk of prostate cancer in a case-control analysis nested within the European Prospective Investigation into Cancer and Nutrition. The American journal of clinical nutrition. 2008;88(5):1353-1363.

35. Persad RA, Gillatt DA, Heinemann D, Habib NA, Smith PJ. Erythrocyte stearic to oleic acid ratio in prostatic carcinoma. British journal of urology. 1990;65(3):268-270.

36. Mikirova N, Riordan HD, Jackson JA, Wong K, Miranda-Massari JR, Gonzalez MJ. Erythrocyte membrane fatty acid composition in cancer patients. Puerto Rico health sciences journal. 2004;23(2):107-113.

37. Kositsawat J, Flanigan RC, Meydani M, Choi YK, Freeman VL. The ratio of oleic-to- stearic acid in the prostate predicts biochemical failure after radical prostatectomy for localized prostate cancer. The Journal of urology. 2007;178(6):2391-2396; discussion 2396.

38. Crowe FL, Appleby PN, Travis RC etal. Circulating fatty acids and prostate cancer risk: individual participant meta-analysis of prospective studies. Journal of the National Cancer Institute. 2014;106(9).

39. Schuurman AG, van den Brandt PA, Dorant E, Brants HA, Goldbohm RA. Association of energy and fat intake with prostate carcinoma risk: results from The Netherlands Cohort Study. Cancer. 1999;86(6):10191027.

40. Freeman VL, Flanigan RC, Meydani M. Prostatic fatty acids and cancer recurrence after radical prostatectomy for early-stage prostate cancer. Cancer causes \& control : CCC. 2007;18(2):211-218.

41. Liss MA, Al-Bayati O, Gelfond J et al. Higher baseline dietary fat and fatty acid intake is associated with increased risk of incident prostate cancer in the SABOR study. Prostate cancer and prostatic diseases. 2018.

42. Uehara H, Takahashi T, Oha M, Ogawa H, Izumi K. Exogenous fatty acid binding protein 4 promotes human prostate cancer cell progression. International journal of cancer. 2014;135(11):2558-2568.

43. Liotti A, Cosimato V, Mirra P et al. Oleic acid promotes prostate cancer malignant phenotype via the G protein-coupled receptor FFA1/GPR40. Journal of cellular physiology. 2018;233(9):7367-7378.

44. Bartsch H, Nair J, Owen RW. Dietary polyunsaturated fatty acids and cancers of the breast and colorectum: emerging evidence for their role as risk modifiers. Carcinogenesis. 1999;20(12):2209-2218.

45. Hodge AM, English DR, McCredie MR et al. Foods, nutrients and prostate cancer. Cancer causes \& control : CCC. 2004;15(1):11-20.

46. Jackson MD, Walker SP, Simpson-Smith CM et al. Associations of whole-blood fatty acids and dietary intakes with prostate cancer in Jamaica. Cancer causes \& control : CCC. 2012;23(1):23-33.

47. Bassett JK, Severi G, Hodge AM et al. Plasma phospholipid fatty acids, dietary fatty acids and prostate cancer risk. International journal of cancer. 2013;133(8):1882-1891.

48. Yang YJ, Lee SH, Hong SJ, Chung BC. Comparison of fatty acid profiles in the serum of patients with prostate cancer and benign prostatic hyperplasia. Clinical biochemistry. 1999;32(6):405-409.

49. Freeman VL, Meydani M, Yong S et al. Prostatic levels of fatty acids and the histopathology of localized prostate cancer. The Journal of urology. 2000;164(6):2168- 2172. 
50. Brown MD, Hart C, Gazi E, Gardner P, Lockyer N, Clarke N. Influence of omega-6 PUFA arachidonic acid and bone marrow adipocytes on metastatic spread from prostate cancer. British journal of cancer. 2010;102(2):403-413.

51. Ritch CR, Wan RL, Stephens LB et al. Dietary fatty acids correlate with prostate cancer biopsy grade and volume in Jamaican men. The Journal of urology. 2007;177(1):97-101; discussion 101.

52. Williams CD, Whitley BM, Hoyo $C$ et al. A high ratio of dietary $n-6 / n-3$ polyunsaturated fatty acids is associated with increased risk of prostate cancer. Nutrition research (New York, NY). 2011;31(1):1-8.

53. Friedrichs W, Ruparel SB, Marciniak RA, deGraffenried L. Omega-3 fatty acid inhibition of prostate cancer progression to hormone independence is associated with suppression of mTOR signaling and androgen receptor expression. Nutrition and cancer. 2011;63(5):771-777.

54. Zhao Z, Reinstatler L, Klaassen Z et al. The Association of Fatty Acid Levels and Gleason Grade among Men Undergoing Radical Prostatectomy. PLoS One. 2016;11(11):e0166594.

55. Newcomer LM, King IB, Wicklund KG, Stanford JL. The association of fatty acids with prostate cancer risk. The Prostate. 2001;47(4):262-268.

56. Schumacher MC, Laven B, Petersson F et al. A comparative study of tissue omega- 6 and omega-3 polyunsaturated fatty acids (PUFA) in benign and malignant pathologic stage pT2a radical prostatectomy specimens. Urologic oncology. 2013;31(3):318-324.

57. Brasky TM, Darke AK, Song X et al. Plasma phospholipid fatty acids and prostate cancer risk in the SELECT trial. Journal of the National Cancer Institute. 2013;105(15):1132- 1141.

58. Leitzmann MF, Stampfer MJ, Michaud DS et al. Dietary intake of n-3 and n-6 fatty acids and the risk of prostate cancer. The American journal of clinical nutrition. 2004;80(1):204-216.

59. Jones PJH RT. Lipids, sterols, and their metabolites. In: Ross AC, Caballero B, Cousins RJ, Tucker KL, Ziegler TR, eds. Modern Nutrition in Health and Disease 11th ed. 2014.

60. Domenichiello AF, Kitson AP, Chen CT, Trepanier MO, Stavro PM, Bazinet RP. The effect of linoleic acid on the whole body synthesis rates of polyunsaturated fatty acids from alpha-linolenic acid and linoleic acid in free-living rats. The Journal of nutritional biochemistry. 2016;30:167-176.

61. Chua ME, Sio MC, Sorongon MC, Dy JS. Relationship of dietary intake of omega-3 and omega-6 Fatty acids with risk of prostate cancer development: a meta-analysis of prospective studies and review of literature. Prostate cancer. 2012;2012:826254.

62. Fu YQ Zheng JS, Yang B, Li D. Effect of individual omega-3 fatty acids on the risk of prostate cancer: a systematic review and dose-response meta-analysis of prospective cohort studies. Journal of epidemiology. 2015;25(4):261-274.

63. Brouwer IA. Omega-3 PUFA: good or bad for prostate cancer? Prostaglandins, leukotrienes, and essential fatty acids. 2008;79(3-5):97-99.

64. Brouwer IA, Katan MB, Zock PL. Dietary alpha-linolenic acid is associated with reduced risk of fatal coronary heart disease, but increased prostate cancer risk: a meta-analysis. The Journal of nutrition. 2004;134(4):919-922.

65. De Stefani E, Deneo-Pellegrini H, Boffetta P, Ronco A, Mendilaharsu M. Alpha-linolenic acid and risk of prostate cancer: a case-control study in Uruguay. Cancer epidemiology, biomarkers \& prevention: a 
publication of the American Association for Cancer Research, cosponsored by the American Society of Preventive Oncology. 2000;9(3):335- 338.

66. Giovannucci E, Rimm EB, Colditz GA et al. A prospective study of dietary fat and risk of prostate cancer. Journal of the National Cancer Institute. 1993;85(19):1571-1579.

67. Sorongon-Legaspi MK, Chua M, Sio MC, Morales M, Jr. Blood level omega-3 Fatty acids as risk determinant molecular biomarker for prostate cancer. Prostate cancer. 2013;2013:875615.

68. Wu J, Wilson KM, Stampfer MJ, Willett WC, Giovannucci EL. A 24-year prospective study of dietary alphalinolenic acid and lethal prostate cancer. International journal of cancer. 2018;142(11):2207-2214.

69. Shannon J, O’Malley J, Mori M, Garzotto M, Palma AJ, King IB. Erythrocyte fatty acids and prostate cancer risk: a comparison of methods. Prostaglandins, leukotrienes, and essential fatty acids. 2010;83(3):161169.

70. Khankari NK, Murff HJ, Zeng C et al. Polyunsaturated fatty acids and prostate cancer risk: a Mendelian randomisation analysis from the PRACTICAL consortium. British journal of cancer. 2016;115(5):624-631.

71. Meng H, Shen Y, Shen J, Zhou F, Shen S, Das UN. Effect of n-3 and n- 6 unsaturated fatty acids on prostate cancer (PC-3) and prostate epithelial (RWPE-1) cells in vitro. Lipids in health and disease. 2013;12:160.

72. Li J, Gu Z, Pan Y et al. Dietary supplementation of alpha-linolenic acid induced conversion of n-3 LCPUFAs and reduced prostate cancer growth in a mouse model. Lipids in health and disease. 2017;16(1):136.

73. Bishop KS, Erdrich S, Karunasinghe $\mathrm{N}$ et al. An investigation into the association between DNA damage and dietary fatty acid in men with prostate cancer. Nutrients. 2015;7(1):405-422.

74. Christensen JH, Fabrin K, Borup K, Barber N, Poulsen J. Prostate tissue and leukocyte levels of n-3 polyunsaturated fatty acids in men with benign prostate hyperplasia or prostate cancer. BJU international. 2006;97(2):270-273.

75. Simon JA, Chen YH, Bent S. The relation of alpha-linolenic acid to the risk of prostate cancer: a systematic review and meta-analysis. The American journal of clinical nutrition. 2009;89(5):1558s-1564s.

76. Brouwer IA, Geleijnse JM, Klaasen VM et al. Effect of alpha linolenic acid supplementation on serum prostate specific antigen (PSA): results from the alpha omega trial. PLoS One. 2013;8(12):e81519.

77. Godley PA, Campbell MK, Miller C et al. Correlation between biomarkers of omega-3 fatty acid consumption and questionnaire data in African American and Caucasian United States males with and without prostatic carcinoma. Cancer epidemiology, biomarkers \& prevention : a publication of the American Association for Cancer Research, cosponsored by the American Society of Preventive Oncology. 1996;5(2):115-119.

78. Ramon JM, Bou R, Romea $S$ et al. Dietary fat intake and prostate cancer risk: a case- control study in Spain. Cancer causes \& control : CCC. 2000;11(8):679-685.

79. Godley PA, Campbell MK, Gallagher P, Martinson FE, Mohler JL, Sandler RS. Biomarkers of essential fatty acid consumption and risk of prostatic carcinoma. Cancer epidemiology, biomarkers \& prevention: a publication of the American Association for Cancer Research, cosponsored by the American Society of Preventive Oncology. 1996;5(11):889-895.

80. Eser PO, Vanden Heuvel JP, Araujo J, Thompson JT. Marine- and plant-derived omega-3 fatty acids differentially regulate prostate cancer cell proliferation. Molecular and clinical oncology. 2013;1(3):444452. 
81. Pandalai PK, Pilat MJ, Yamazaki K, Naik H, Pienta KJ. The effects of omega-3 and omega-6 fatty acids on in vitro prostate cancer growth. Anticancer research. 1996;16(2):815-820.

82. Liang P, Henning SM, Guan J et al. Role of Host GPR120 in Mediating Dietary Omega-3 Fatty Acid Inhibition of Prostate Cancer. Journal of the National Cancer Institute. 2018.

83. Aronson WJ, Kobayashi N, Barnard RJ et al. Phase II prospective randomized trial of a low-fat diet with fish oil supplementation in men undergoing radical prostatectomy. Cancer prevention research (Philadelphia, Pa). 2011;4(12):2062-2071.

84. Demark-Wahnefried W, Polascik TJ, George SL et al. Flaxseed supplementation (not dietary fat restriction) reduces prostate cancer proliferation rates in men presurgery. Cancer epidemiology, biomarkers \& prevention : a publication of the American Association for Cancer Research, cosponsored by the American Society of Preventive Oncology. 2008;17(12):3577-3587.

85. Azrad M, Demark-Wahnefried W. Dietary omega-6 and omega-3 fatty acids and prostate cancer - letter. Cancer prevention research (Philadelphia, Pa). 2012;5(5):798; author reply 799.

86. Bang HO, Dyerberg J, Sinclair HM. The composition of the Eskimo food in north western Greenland. The American journal of clinical nutrition. 1980;33(12):2657-2661.

87. Karmali RA, Marsh J, Fuchs C. Effect of omega-3 fatty acids on growth of a rat mammary tumor. Journal of the National Cancer Institute. 1984;73(2):457-461.

88. Karmali RA, Reichel P, Cohen LA et al. The effects of dietary omega-3 fatty acids on the DU-145 transplantable human prostatic tumor. Anticancer research. 1987;7(6):1173- 1179.

89. Chavarro JE, Stampfer MJ, Hall MN, Sesso HD, Ma J. A 22-y prospective study of fish intake in relation to prostate cancer incidence and mortality. The American journal of clinical nutrition. 2008;88(5):12971303.

90. Norrish AE, Skeaff CM, Arribas GL, Sharpe SJ, Jackson RT. Prostate cancer risk and consumption of fish oils: a dietary biomarker-based case-control study. British journal of cancer. 1999;81(7):1238-1242.

91. Terry P, Lichtenstein P, Feychting M, Ahlbom A, Wolk A. Fatty fish consumption and risk of prostate cancer. Lancet (London, England). 2001;357(9270):1764-1766.

92. Patel D, Thevenet-Morrison K, van Wijngaarden E. Omega-3 polyunsaturated fatty acid intake through fish consumption and prostate specific antigen level: results from the 2003 to 2010 National Health and Examination Survey. Prostaglandins, leukotrienes, and essential fatty acids. 2014;91(4):155-160.

93. Ukoli FA, Fowke JH, Akumabor P et al. The association of plasma fatty acids with prostate cancer risk in African Americans and Africans. Journal of health care for the poor and underserved. 2010;21(1 Suppl):127147.

94. Ukoli FA, Akumabor PN, Oguike TC, Dent LL, Beech D, Osime U. The association of plasma fatty acids with prostate cancer risk in Nigerians. Ethnicity \& disease. 2009;19(4):454-461.

95. Zhang Z, Garzotto M, Beer TM et al. Effects of omega-3 Fatty Acids and Catechins on Fatty Acid Synthase in the Prostate: A Randomized Controlled Trial. Nutrition and cancer. 2016;68(8):1309-1319.

96. Zhao H, Pflug BR, Lai X, Wang M. Pyruvate dehydrogenase alpha 1 as a target of omega-3 polyunsaturated fatty acids in human prostate cancer through a global phosphoproteomic analysis. Proteomics. 2016;16(17):2419-2431. 
97. Figiel S, Pinault M, Domingo I et al. Fatty acid profile in peri-prostatic adipose tissue and prostate cancer aggressiveness in African-Caribbean and Caucasian patients. European journal of cancer (Oxford, England: 1990). 2018;91:107-115.

98. Freeman VL, Meydani M, Hur K, Flanigan RC. Inverse association between prostatic polyunsaturated fatty acid and risk of locally advanced prostate carcinoma. Cancer. 2004;101(12):2744-2754.

99. Wang $\mathrm{S}, \mathrm{Wu} \mathrm{J}$, Suburu J et al. Effect of dietary polyunsaturated fatty acids on castration- resistant Pten-null prostate cancer. Carcinogenesis. 2012;33(2):404-412.

100. Moreel $X$, Allaire J, Leger $C$ et al. Prostatic and dietary omega- 3 fatty acids and prostate cancer progression during active surveillance. Cancer prevention research (Philadelphia, Pa). 2014;7(7):766-776.

101. Begin ME, Das UN, Ells G, Horrobin DF. Selective killing of human cancer cells by polyunsaturated fatty acids. Prostaglandins, leukotrienes, and medicine. 1985;19(2):177- 186.

102. Chua ME, Sio MC, Sorongon MC, Morales ML, Jr. The relevance of serum levels of long chain omega-3 polyunsaturated fatty acids and prostate cancer risk: A meta-analysis. Canadian Urological Association journal = Journal de l'Association des urologues du Canada. 2013;7(5-6):E333-343.

103. McEntee MF, Ziegler C, Reel D et al. Dietary n-3 polyunsaturated fatty acids enhance hormone ablation therapy in androgen-dependent prostate cancer. The American journal of pathology. 2008;173(1):229241.

104. Wang X, Breeze A, Kulka M. N-3 polyunsaturated fatty acids inhibit IFN-gamma- induced IL-18 binding protein production by prostate cancer cells. Cancer immunology, immunotherapy : CII. 2015;64(2):249258.

105. Chung BH, Mitchell SH, Zhang JS, Young CY. Effects of docosahexaenoic acid and eicosapentaenoic acid on androgen-mediated cell growth and gene expression in LNCaP prostate cancer cells. Carcinogenesis. 2001;22(8):1201-1206.

106. Liu Z, Hopkins MM, Zhang Z et al. Omega-3 fatty acids and other FFA4 agonists inhibit growth factor signaling in human prostate cancer cells. The Journal of pharmacology and experimental therapeutics. 2015;352(2):380-394.

107. Motaung E, Prinsloo SE, van Aswegen CH, du Toit PJ, Becker PJ, du Plessis DJ. Cytotoxicity of combined essential fatty acids on a human prostate cancer cell line. Prostaglandins, leukotrienes, and essential fatty acids. 1999;61(5):331-337.

108. Pan J, Zhou S, Xiang R et al. An Omega-3 fatty acid desaturase-expressing gene attenuates prostate cancer proliferation by cell cycle regulation. Oncology letters. 2017;13(5):3717-3721.

109. Rose DP, Connolly JM. Effects of fatty acids and eicosanoid synthesis inhibitors on the growth of two human prostate cancer cell lines. The Prostate. 1991;18(3):243-254.

110. Yi L, Zhang QY, Mi MT. [Role of Rho GTPase in inhibiting metastatic ability of human prostate cancer cell line PC-3 by omega-3 polyunsaturated fatty acid]. Ai zheng = Aizheng = Chinese journal of cancer . 2007;26(12):1281-1286.

111. Aronson WJ, Glaspy JA, Reddy ST, Reese D, Heber D, Bagga D. Modulation of omega- 3/omega-6 polyunsaturated ratios with dietary fish oils in men with prostate cancer. Urology. 2001;58(2):283-288.

112. Higashihara E, Itomura $\mathrm{M}$, Terachi $\mathrm{T}$ et al. Effects of eicosapentaenoic acid on biochemical failure after radical prostatectomy for prostate cancer. In vivo (Athens, Greece). 2010;24(4):561-565. 
113. Guertin MH, Robitaille K, Pelletier JF et al. Effects of concentrated long-chain omega-3 polyunsaturated fatty acid supplementation before radical prostatectomy on prostate cancer proliferation, inflammation, and quality of life: study protocol for a phase IIb, randomized, double-blind, placebo-controlled trial. $B M C$ cancer. 2018;18(1):64.

114. Liang P, Henning SM, Schokrpur S et al. Effect of Dietary Omega-3 Fatty Acids on Tumor-Associated Macrophages and Prostate Cancer Progression. The Prostate. 2016;76(14):1293-1302.

115. Vissapragada S, Ghosh A, Ringer L et al. Dietary n-3 polyunsaturated fatty acids fail to reduce prostate tumorigenesis in the PB-ErbB-2 x Pten(+/-) preclinical mouse model. Cell cycle (Georgetown, Tex). 2010;9(9):1824-1829.

116. Patterson AC, Stark KD. Direct determinations of the fatty acid composition of daily dietary intakes incorporating nutraceuticals and functional food strategies to increase n-3 highly unsaturated fatty acids. Journal of the American College of Nutrition. 2008;27(5):538-546.

117. Pauwels EK, Kairemo K. Fatty acid facts, part II: role in the prevention of carcinogenesis, or, more fish on the dish? Drug news \& perspectives. 2008;21(9):504- 510.

118. Norrish AE, Jackson RT, Sharpe SJ, Skeaff CM. Men who consume vegetable oils rich in monounsaturated fat: their dietary patterns and risk of prostate cancer (New Zealand). Cancer causes \& control : CCC. 2000;11(7):609-615.

119. Mamalakis G, Kafatos A, Kalogeropoulos N, Andrikopoulos N, Daskalopulos G, Kranidis A. Prostate cancer vs hyperplasia: relationships with prostatic and adipose tissue fatty acid composition. Prostaglandins, leukotrienes, and essential fatty acids. 2002;66(5-6):467-477.

120. Cavazos DA, Price RS, Apte SS, deGraffenried LA. Docosahexaenoic acid selectively induces human prostate cancer cell sensitivity to oxidative stress through modulation of NF-kappaB. The Prostate. 2011;71(13):1420-1428.

121. Shaikh IA, Brown I, Wahle KW, Heys SD. Enhancing cytotoxic therapies for breast and prostate cancers with polyunsaturated fatty acids. Nutrition and cancer. 2010;62(3):284- 296.

122. Bianchini F, Giannoni E, Serni S, Chiarugi P, Calorini L. 22 : 6n-3 DHA inhibits differentiation of prostate fibroblasts into myofibroblasts and tumorigenesis. The British journal of nutrition. 2012;108(12):21292137.

123. Gu Z, Wu J, Wang $\mathrm{S}$ et al. Polyunsaturated fatty acids affect the localization and signaling of PIP3/AKT in prostate cancer cells. Carcinogenesis. 2013;34(9):1968-1975.

124. Hu Z, Qi H, Zhang R et al. Docosahexaenoic acid inhibits the growth of hormone- dependent prostate cancer cells by promoting the degradation of the androgen receptor. Molecular medicine reports. 2015;12(3):37693774.

125. Narayanan NK, Narayanan BA, Reddy BS. A combination of docosahexaenoic acid and celecoxib prevents prostate cancer cell growth in vitro and is associated with modulation of nuclear factor-kappaB, and steroid hormone receptors. International journal of oncology. 2005;26(3):785-792.

126. Shaikh IA, Brown I, Schofield AC, Wahle KW, Heys SD. Docosahexaenoic acid enhances the efficacy of docetaxel in prostate cancer cells by modulation of apoptosis: the role of genes associated with the NFkappaB pathway. The Prostate. 2008;68(15):1635-1646.

127. Wang HH, Hung TM, Wei J, Chiang AN. Fish oil increases antioxidant enzyme activities in macrophages and reduces atherosclerotic lesions in apoE-knockout mice. Cardiovascular research. 2004;61(1):169-176. 
128. Chisaki K, Okuda Y, Suzuki S et al. Eicosapentaenoic acid suppresses basal and insulin- stimulated endothelin-1 production in human endothelial cells. Hypertension research : official journal of the Japanese Society of Hypertension. 2003;26(8):655-661.

129. Lopez D, Orta X, Casos K et al. Upregulation of endothelial nitric oxide synthase in rat aorta after ingestion of fish oil-rich diet. American journal of physiology Heart and circulatory physiology. 2004;287(2):H567572.

130. Bonaa KH, Bjerve KS, Straume B, Gram IT, Thelle D. Effect of eicosapentaenoic and docosahexaenoic acids on blood pressure in hypertension. A population-based intervention trial from the Tromso study. The New England journal of medicine. 1990;322(12):795-801.

131. Burr ML, Fehily AM, Gilbert JF et al. Effects of changes in fat, fish, and fibre intakes on death and myocardial reinfarction: diet and reinfarction trial (DART). Lancet (London, England). 1989;2(8666):757-761.

132. Jain AP, Aggarwal KK, Zhang PY. Omega-3 fatty acids and cardiovascular disease. European review for medical and pharmacological sciences. 2015;19(3):441-445.

133. Straka S, Lester JL, Cole RM et al. Incorporation of eicosapentaenioic and docosahexaenoic acids into breast adipose tissue of women at high risk of breast cancer: a randomized clinical trial of dietary fish and n-3 fatty acid capsules. Molecular nutrition \& food research. 2015;59(9):1780-1790.

134. Sharma G, Rani I, Bhatnagar A, Agnihotri N. Apoptosis-Mediated Chemoprevention by Different Ratios of Fish Oil in Experimental Colon Carcinogenesis. Cancer investigation. 2016;34(5):220-230.

135. Wen X, Reynolds L, Mulik RS et al. Hepatic Arterial Infusion of Low-Density Lipoprotein Docosahexaenoic Acid Nanoparticles Selectively Disrupts Redox Balance in Hepatoma Cells and Reduces Growth of Orthotopic Liver Tumors in Rats. Gastroenterology. 2016;150(2):488-498.

136. Haqq J, Howells LM, Garcea G, Dennison AR. Targeting pancreatic cancer using a combination of gemcitabine with the omega-3 polyunsaturated fatty acid emulsion, Lipidem. Molecular nutrition \& food research. 2016;60(6):1437-1447.

137. Anderson BM, Ma DW. Are all n-3 polyunsaturated fatty acids created equal? Lipids in health and disease. 2009;8:33.

138. Stanford JL, King I, Kristal AR. Long-term storage of red blood cells and correlations between red cell and dietary fatty acids: results from a pilot study. Nutrition and cancer. 1991;16(3-4):183-188.

139. Poppitt SD, Kilmartin P, Butler P, Keogh GF. Assessment of erythrocyte phospholipid fatty acid composition as a biomarker for dietary MUFA, PUFA or saturated fatty acid intake in a controlled cross-over intervention trial. Lipids in health and disease. 2005;4:30.

140. Shannon J, King IB, Moshofsky R et al. Erythrocyte fatty acids and breast cancer risk: a case-control study in Shanghai, China. The American journal of clinical nutrition. 2007;85(4):1090-1097.

141. Karlsson M, Marild S, Brandberg J, Lonn L, Friberg P, Strandvik B. Serum phospholipid fatty acids, adipose tissue, and metabolic markers in obese adolescents. Obesity (Silver Spring, Md). 2006;14(11):1931-1939.

142. Freeman VL, Meydani M, Yong S et al. Assessing the effect of fatty acids on prostate carcinogenesis in humans: does self-reported dietary intake rank prostatic exposure correctly? The American journal of clinical nutrition. 2001;73(4):815-820.

143. Kuhajda FP. Fatty acid synthase and cancer: new application of an old pathway. Cancer research. 2006;66(12):5977-5980. 


\section{Controversies Surrounding Omega-3 Fatty Acids and Prostate Cancer}

144. Mashima T, Seimiya H, Tsuruo T. De novo fatty-acid synthesis and related pathways as molecular targets for cancer therapy. British journal of cancer. 2009;100(9):1369-1372.

145. Migita T, Ruiz S, Fornari A et al. Fatty acid synthase: a metabolic enzyme and candidate oncogene in prostate cancer. Journal of the National Cancer Institute. 2009;101(7):519- 532.

146. Azrad M, Zhang K, Vollmer RT et al. Prostatic alpha-linolenic acid (ALA) is positively associated with aggressive prostate cancer: a relationship which may depend on genetic variation in ALA metabolism. PLoS One. 2012;7(12):e53104.

147. Gruz P, Shimizu M, Sugiyama KI, Honma M. Mutagenicity of omega-3 fatty acid peroxidation products in the Ames test. Mutation research. 2017;819:14-19.

Citation: Xinchun Zhou, MD, PhD, Akram Shalaby, MD, Timothy C. Allen, MD, JD. "Controversies Surrounding Omega-3 Fatty Acids and Prostate Cancer". American Research Journal of Urology, 2019; 3(1): 1-19.

Copyright (c) 2019 Xinchun Zhou, MD, PhD, Akram Shalaby, MD, Timothy C. Allen, MD, JD. This is an open access article distributed under the Creative Commons Attribution License, which permits unrestricted use, distribution, and reproduction in any medium, provided the original work is properly cited. 